\title{
LV. Colour-sensation
}

\section{H.R. Droop M.A.}

To cite this article: H.R. Droop M.A. (1883) LV. Colour-sensation, Philosophical Magazine Series

5, 15:96, 373-384, DOI: $10.1080 / 14786448308627369$

To link to this article: http://dx.doi.org/10.1080/14786448308627369

$$
\text { 册 Published online: } 28 \text { Apr } 2009 .
$$

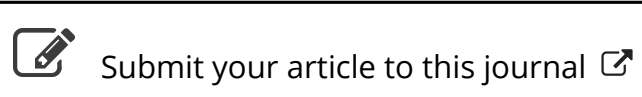

\footnotetext{
Џll Article views: 3
}

Q View related articles $\sqsubset$ 


\title{
PHILOSOPHICAL MAGAZINE
}

\author{
AND \\ JOURNAL OF SCIENCE. \\ [FIFTH SERIES.] \\ JUNE 1883.
}

LV. Colour-Sensation. By H. R. Droop, M.A.*

THE generally received theory of colour-sensation is that 1 there are three colour-senses in the eye, and that all the different impressions of colour received by the brain are due to those three colour-senses being affected in different proportions by the light entering the eye. This theory was originally propounded by Young, and was revived by Helmholtz and Maxwell, who established experimentally certain laws of colour-sensation, from which laws the theory of three coloursensations was a probable, but (as I shall show further on) not a necessary, inference.

Maxwell proved experimentally $\dagger$ that a linear equation of the form

$$
\mathrm{X}=v \mathrm{~V}+c \mathrm{C}+u \mathrm{U}
$$

could always be found, expressing any colour and shade of colour perceived by the normally constituted eye in the terms of any three given colours (whether pigments-e.g. vermilion, chrome yellow, and ultramarine-or selected rays of the spectrum) as seen by the same eye. This equation, when the coefficients $v, c$, and $u$ are all positive (i.e. when the three given colours are sufficiently intense and distinct from each other), means that the colour $\mathrm{X}$ could be produced by combining together (i.e. presenting to the eye simultaneously) certain proportions of the three given colours. From this it obviously

* Communicated by the Physical Society ; read April 28, 1883.

+ See Transactions of the Royal Society of Edinburgh, vol. xxi.; Philosophical Transactions, 1860, p. 57.

Phil. Mag. S. 5. Vol. 15. No. 96. June 1883. $2 \mathrm{E}$ 
followed that every such colour and shade could be produced by three colour-sensations, each of which, when excited, conveyed to the brain the impression of a homogeneous colour.

Helmholtz arrived at the same conclusion by proving (see Handbuch der physiologischen Optik, p. 282, ed. 1867) that any given colour could be produced by combining a certain quantity of white with some particular colour of the spectrum. From which he deduced that every colour and shade of colour depended on only three independent variables, viz. the quantity of the spectrum-colour, the quantity of white, and the length of wave of the spectrum-colour. But though the theory of three colour-sensations was the simplest and most obvious explanation of the experimental facts thus established, it is not (as has been commonly assumed) the only theory capable of explaining them. They would be equally well explained by supposing that there are four, five, or more colour-sensations connected by a sufficient number of linear equations of condition to reduce the number of independent variables to three. Obviously this will satisfy all that Helmholtz established. That it will also explain the law established by Maxwell may be shown as follows.

Suppose that there are four colour-sensations, R, Y, G, and $B$ (the red, yellow, green, and blue sensations), and that each of them is expressed as a linear function of the three standard colours, V, C, and U, as every colour seen by a normal human eye can be expressed.

Then we shall have four equations of the form

$$
\left.\begin{array}{l}
\mathrm{R}=v_{r} \mathrm{~V}+c_{r} \mathrm{C}+u_{r} \mathrm{U}, \\
\mathrm{Y}=v_{y} \mathrm{~V}+c_{y} \mathrm{C}+u_{y} \mathrm{U}, \\
\mathrm{G}=v_{g} \mathrm{~V}+c_{g} \mathrm{C}+u_{g} \mathrm{U}, \\
\mathrm{B}=v_{b} \mathrm{~V}+c_{b} \mathrm{C}+u_{b} \mathrm{U} .
\end{array}\right\}
$$

And when we eliminate $V, C$, and $U$ between these four equations we shall get a linear relation between $R, Y, G$, and $B$, which is the condition that these four colour-sensations should be capable of being expressed as linear functions of $V$, $\mathrm{C}$, and $\mathrm{U}, i$. e. should be colour-sensations coexisting in a normal eye.

If we supposed five colour-sensations, we should have five equations (A) between which to eliminate $\mathrm{V}, \mathrm{C}$, and $\mathrm{U}$, and should get two linear equations between the five coloursensations.

The proposition that four colour-sensations with a linear relation between them will satisfy Maxwell's law may also be tested in another way, viz. by assuming that there are four colour-sensations connected by a linear equation

$$
r \mathrm{R}+y \mathrm{Y}+g \mathrm{G}+b \mathrm{~B}=0, . . . .
$$


and that $\mathrm{V}, \mathrm{C}$, and $\mathrm{U}$, the three standard colours, are known to result from these colour-sensations being effected in certain proportions.

E. g. $\mathrm{V}$ is known to result from $\mathrm{R}$, the red colour-sensation, being effected to an extent $r_{v}, \mathrm{Y}$ to an extent $y_{v}, \mathrm{G}$ to an extent $g_{v}$, and $\mathrm{B}$ to an extent $b_{v}$; and may therefore be represented by the equation

$$
\mathrm{V}=r_{v} \mathrm{R}+y_{v} \mathrm{Y}+g_{v} \mathrm{G}+b_{v} \mathrm{~B} ; \quad . \quad . \quad .
$$

and similarly $\mathrm{C}$ and $\mathrm{U}$ may be represented by

$$
\begin{aligned}
& \mathrm{C}=r_{c} \mathrm{R}+y_{c} \mathrm{Y}+g_{c} \mathrm{G}+b_{c} \mathrm{~B}, \quad . \quad . \\
& \mathrm{U}=r_{u} \mathrm{R}+y_{u} \mathrm{Y}+g_{u} \mathrm{G}+b_{u} \mathrm{~B} . \quad . \quad . \quad \text {. }
\end{aligned}
$$

Then from these four equations we can express $R, Y, G$, and $\mathrm{B}$ as linear functions of $\mathrm{V}, \mathrm{C}, \mathrm{U}$. But every possible colour $\mathrm{X}$ must be produced by exciting all or some of the four coloursensations, and therefore must be capable of being expressed by an equation

$$
\mathrm{X}=r_{x} \mathrm{R}+y_{x} \mathrm{Y}+g_{x} \mathrm{G}+b_{x} \mathrm{~B} \text {. }
$$

Consequently, if $R, Y, G$, and $B$ be replaced in this equation by the linear functions of $\mathrm{V}, \mathrm{C}$, and $\mathrm{U}$ which represent them, every such colour $\mathrm{X}$ can be expressed as a linear function of $\mathrm{V}, \mathrm{C}$, and $\mathrm{U}$; i. e. every such colour will conform to the law, which Maxwell and Helmholtz established, of being capable of being made up of any three standard colours.

The same reasoning might obviously be applied in like manner to five colour-sensations connected by two linear equations of condition, or to $n$ colour-sensations connected by $n-3$ linear equations of condition.

I have taken up this question and endeavoured to show that what Maxwell and Helmholtz established is not inconsistent with the existence of four or more colour-sensations (provided certain relations exist between them), because a certain recent discovery seems to me to have given a particular hypothesis, involving four colour-sensations, a strong claim to be accepted as, in the main, true. This discovery relates to the colours actually seen by colour-blind persons. Two persons have been discovered who, being each colour-blind of only one eye, can explain how far the colours seen by their colour-blind eyes agree with, or differ from, those seen by their normal eyes. It has been found that each of these persons has two coloursensations complementary to each other. One sees yellow and blue, and is blind to red and green; while the other sees red and bluish green, and is blind to blue and yellow; and with each of them the combination of his two colour-sensations in proper proportions produces white or grey. Professor Holmgren, of Upsala, has given an account of both these cases in the 'Proceedings of the Royal Society,' vol. xxxi. p. 302; and Pro$2 \ddot{\mathrm{F}} 2$ 
fessor Hippel, of Giessen, has given an account (differing in some respects) of the first or blue-yellow case in Gräf's Aretiv für Ophthalmologie, vol. xxvi. p. 176, vol. xxvii. pt. 3, p. 47.

These two cases suggested to Professor Preyer of Jena a theory (which he propounded in 1881 in Pflüger's Archiv, vol. xxv.) that ordinary eyes have two pairs of colour-sensations-(1) yellow and blue, and (2) red and bluish green, and that the colour-blindness which consists in confusing red and green, or, as the case may be, blue and yellow, is due to the absence of one pair of these sensations. But Professor Preyer does not deal with the difficulty that Helmholtz and Maxwell are supposed to have proved, that there cannot be more than three colour-sensations, although that view is treated as unquestionable by other recent writers, e. g. by Professor Donders (Gräf's Archiv für Ophthalmologie, vol. xxvii.), and by Professor v. Kries, of Freiburg im Breisgau (Die Gesichtsempfindungen und ithe Analyse, Leipzig 1882, p. 33); and it is naturally a serious obstacle to the fair consideration of Professor Preyer's theory.

But inasmuch as Professor Preyer supposes that in each pair of his colour-sensations the one sensation is complementary to the other, we have the equation

$$
R+G=\text { White }=Y+B \text {, }
$$

a linear relation between the four colour-sensations; and therefore it follows, from what I have already proved, that this hypothesis of two pairs of complementary colour-sensations is quite consistent with what Maxwell and Helmholtz established.

This theory of Professor Preyer's explains the leading facts of colour-blindness, viz. that a colour-blind eye only perceives two homogeneous colours, and that it is unable to distinguish between red and green, or, as the case may be, between blue and yellow. It is impossible to ascertain with absolute certainty that persons who are colour-blind with both eyes see the same colours as the two persons who have been discovered colour-blind of only one eye; but it is noteworthy that when Dr. Pole made that minute examination of his colour-blindness, the results of which he gave in the 'Philosophical Transactions' for 1859, he came to the conclusion that the colours he saw were yellow and blue and, as the result of their mixture, white; and he only gave up this view in deference to the three-sensation theory then supposed to be conclusively established.

The following facts, not connected with colour-blindness, seem to me to give considerable support to the hypothesis of two pairs of complementary colour-sensations:-

(1) Observations have been made as to the sensibility of 
different parts of the retina to different colours, and also as to the effect of diminishing the angles subtended at the eye by small coloured objects; and in both cases red and green colours are found to comport themselves alike, and differently from blue and yellow. When an object is viewed more and more indirectly, so that its image moves from the yellow spot towards the circumference of the retina, sensibility to yellow and blue lasts longer than sensibility to red and green; while, on the other hand, if the angular magnitude of the object be diminished, sensibility to red and green lasts longer than sensibility to blue and yellow (von Kries, Gesichtsempfindungen, pp. 93, 95).

(2) In cases where the colour-senses become affected by disease of the eye, the order in which different colours are found to disappear agrees with the theory of four colour-sensations. In cases of atrophy of the optic nerve, it seems pretty clearly established that green becomes invisible first, then red, then yellow, while the perception of blue remains the longest (see Leber, Archiv für Ophthalnnologie, vol. xv.; Leber, Handbuch der Augenheilkunde, vol. v. p. 1039; Schön, Lehre rom Gesichtsfelde und seine Anomalien).

In cases where the sight is affected by excess in alcohol or tobacco, Nuel found that green and red became invisible simultaneously, and blue and yellow later (Annales de l'Oculiste, 80, p. 110 , as cited in von Kries, Gesichtsempfindungen, p. 156).

On the other hand, the received hypothesis of three coloursensations does not readily explain how it is that one colourblind eye sees blue, yellow, and white, and another red, green, and white, as Professors Holmgren and Hippel have found to be the case. If there are only three colour-sensations, it is generally agreed that they must be red, green, and violet. If one of these three sensations were wanting, we should naturally expect that the defective eye would have the other two sensations of a normal eye. For instance, if the red sensation were missing, we should expect that the eye would see green and violet, and white would appear of a bluish green complementary to the missing red. Similarly if green were missing, we should expect that the defective eye would see red and violet; while if violet were missing, it would see red and green, and white would appear yellowish complementary to violet.

The only attempted explanation* I have seen of this pro-

* Professor Holmgren, when communicating the two cases of onesided colour-blindness to the Royal Society, states that he considers these phenomena quite consistent with the theory of three colour-sensations; but he does not explain how he reconciles them with it, except by referring to works which I have not been able to get access to. 
ceeds from Professor Donders, who suggests that where one of the three colour-sensations has been wanting from birth, its absence may have modified the development of the other two sensations. He says:- "The retina is not an instrument with three strings of which one has suddenly snapped. It is a living instrument whose three differently toned strings have been developed in conjunction with each other " (Gräf's Archiv für Ophthalmologie, vol. xxvii. p. 212).

This explanation is ingenious; but it assumes that all cases of colour-blindness to red and green are from birth, whereas, though this is usually so, there are several alleged cases of acquired colour-blindness to red and green. Dr. Joy Jeffries, pp. 50-52, gives two cases, one discovered by Professor Tyndall, the other by Mr. Haynes Walton; and M. Nuel has also described one, Annales de l'Oculiste, 80, 82, as quoted by v. Kries, Gesichtsempfindungen, p. 154.

Moreover Professor Cohn (Deutsche medicinische Wochenschrift, 1880, No. 16, cited by von Kries, p. 158) claims to have temporarily restored to normal colour-vision a person affected with red-green colour-blindness from birth. If this be so, there cannot well have been any such abnormal development of his other colour-sensations as Professor Donders supposes. Such a development could hardly have been suddenly cured by artificial means.

Those colour-blind persons who cannot distinguish between red and green have been divided into two classes, according as they can perceive rays towards the end of the spectrum or are unable to do so. According to many adherents of the theory of three colour-sensations, those who can perceive rays at the red end want the green-colour sense, while those who cannot do so want the red sense. It seems to be established that rays at the green part of the spectrum do not make as much impression on the so-called green-blind as on the socalled red-blind; and Professor Donders has lately ascertained by careful measurements with two cases, one of so-called redblindness, and the other of so-called green-blindness, that throughout the red and orange parts of the spectrum the redblind eye perceives less light than the green-blind eye, and that the opposite is the case in the green portion of the spectrum (Gräf's Archiv für Oplithalmologie, vol. xxvii.; Transactions of the International Medical Congress for 1881, vol. i. p. 277).

But there seem to me to be several serious objections to explaining the difference between so-called green-blind and socalled red-blind by the hypothesis of three colour-sensations:-

(A) If there are only three colour-senses, the green sense 
must be of a yellowish green capable of producing yellow and orange when combined with the red sense, and very different from the bluish green which is complementary to red. Therefore if one class of colour-blind persons have lost the red sense and the other the green sense, there ought to be considerable differences in all the colour equations obtained from the two classes of eyes, and especially in the proportions of blue and yellow which will neutralize each other. But I have not met with any trace of such differences having attracted attention, except in equations between red and green, and it is clear that in the spectrum the neutral point where the blue or violet colour-sense nentralizes the other colour-sense is very nearly the same for red-blind and green-blind persons. Professor Donders fixes it for his red-blind case at a wave-length of 494.85 millionths of a millimetre, and for his green-blind case at $502 \cdot 3$ millionths, the difference $7 \cdot 5$ being not one fiftieth part of the difference between the greatest and least wave-lengths in the visible spectrum; while Professor Preyer, in another case, found that doubling the amount of light altered the neutral point from $512 \cdot 8$ to $506 \cdot 6$, i. e. nearly as much(Pflüger's Archiv, vol. xxv.).

(B) If blindness to the red end of the spectrum were due to the absence of the red sense, it would be the same in extent in different red-blind persons, whereas in fact it differs considerably. (Donders, Gräf's Archiv, vol. xxvii.)

(C) The extent to which the violet end of the spectrum is obscured to violet- or blue-blind eyes also varies very much. Professor Stilling (Klinische Monatsblätter für Augenheilkunde, 1875, Beilage 2) met with three cases in which the green thallium-line between $\mathrm{E}$ and $\mathrm{D}$ formed the boundary of the visible spectrum; while in another case (Centralblatt für praktische Augenheilkunde, 1878, p.99) the same observer found that nearly the whole of the spectral green was perceived, and grey or, in a faint spectrum, red beyond it. In the case of one-eyed violet- or blue-blindness described by Professor Holmgren ('Proceedings of the Royal Society, vol. xxxii. p. 305) "the spectrum is continued over the place where we see green, greenish blue, cyan-blue, and indigo to the commencement of the violet, where it absolutely ended with a sharp limit about Fraunhofer's line G."

(D) As is well known, inability to distinguish between red and green has in many cases been found to exist among different members of the same family, and especially among brothers; and therefore when such colour-blindness is found to exist among relations, there is a very strong probability that they have inherited the same affection of the eyes. Thert- 
fore if red-blindness and green-blindness be distinct things, due to the absence of different colour-senses, we should expect that the colour-blind members of the same family would be either all red-blind or all green-blind. But this is not the case. Among the colour-blind cases examined by Professor Stilling (Klinische Monatsblätter für Augenlzeilkunde, 1875, Beilage 1 and 2) there were two pairs of brothers both unable to distinguish between red and green; and in each case one brother was able to perceive light at the red end of the spectrum, while the other was not.

All these reasons lead me to believe that the difference between so-called red-blind and so-called green-blind is not due to their having lost different colour-senses, but rather to the loss of one pair of colour-senses, those for red and green being, in the case of the so-called red-blind, accompanied by some disturbance of the other pair of colour-senses -a disturbance varying in character and degree in different cases, and similar to what is found to exist in different cases of blue- or violet-blindness.

The shapes of the curves Professor Donders has published (Trans. International Medical Congress, 1881, vol. i. p. 280) to represent the respective intensities of the light perceived by a red-blind and a green-blind eye have suggested to me a possible explanation of the difference between these two eyes. The curves representing the less-refrangible sensation of each eye correspond very nearly in shape and dimensions; but that for the red-blind eye is shifted some way further from the red end of the spectrum. On the other hand, the curves representing the more-refrangible sensation of the two eves are almost identical in position as well as in shape and size. This effect would be produced if the organization producing the less-refrangible (or yellow) colour-sensation in the green-blind eye were so modified in the red-blind eye as to make shorter waves produce the same effects which longer waves produced in a green-blind eye. The change supposed would be equivalent to shifting the tone of a musical instrument an octave higher.

But I do not suppose that all cases of shortened spectrum could be thus accounted for.

In order to show more in detail what my views of coloursensation are, I have prepared a diagram representing roughly how the two pairs of colour-senses are affected by the different rays of the spectrum. The upper half of the diagram represents the effects produced by the: different rays on the yellow and blue colour-senses, and the lower part those they produce on the red and green colour-senses. 
The portion with crossed vertical and horizontal lines represents the extent to which the same rays operate on both the yellow and the blue colour-senses, and thus produce white light, which (combining with the colour produced by the colour-sense which is most affected) produces a whitish yellow or a whitish blue. Similarly the portion crossed by diagonal lines in the lower half of the diagram represents the extent to which the same rays operate on both the red and the green colour-senses.

I have represented the complementary colour-sensations as thus overlapping*, because Professors Preyer and Hippel have found that, for red-green blind eyes, the neutral point in the spectrum which appears white or grey varies in position according to the intensity of the light (Pflüger's Archiv, vol. xxv.; Gräf's Archiv für Ophthalmologie, vol. xxvii. pt. 3). Professor Preyer found that enlarging the aperture through which the light was admitted from 250 millim. to 370 millim. shifted the neutral point, where the spectrum appeared grey, from where the wave-length was $512 \cdot 8$ millionths of a millimetre to where it was $506 \cdot 6$ millionths. This is readily intelligible, if the rays in this part of the spectrum affect both the yellow and the blue colour-senses, while the intensity of the light alters the proportions in which they are respectively affected by it.

It will be observed that a narrow strip of yellow extends nearly to the red end of the spectrum. Professor Holmgren ('Proceedings of the Royal Society') states that the red seen by the violet-blind eye, in his case of one-sided violet-blindness, is not quite identical with the common spectral red of the normal eye, but rather a clearer red having a shade of carmine, about the same as the red towards the end of the subjective spectrum of the normal-eyed. This colour would obviously require a slight admixture of yellow to reduce it to the common spectral red of the normal-eyed. Moreover the extension of the yellow nearly to the red end of the spectrum explains how it is that a great many persons who are red-green colour-blind can see almost to the red end of the spectrum.

The strip of red at the violet end of the spectrum also requires explanation. The colours seen by the red-green blind eye in the case of one-sided red-green blindness are not yellow and violet, but yellow and indigo with only a faint shade of

* The extent to which the colour-sensations are represented as overlapping rests on conjecture. Observations on colour-blind persons, $i$. $e$. persons with only two colour-sensations, give readily the neutral points where the sensatiuns counterbalance each other and produce white; but the extent to which they overlap could only be inferred from,olsserving when the colours cease to have any admixture of white. 
violet in it. Indeed, while Professor Holmgren speaks to the faint shade of violet (' Proceedings of the Royal Society'), Professor Hippel, who discovered this case and had more opportumities of examining it, states that the blue lines of indium and cæsium (which are indigo, not violet) appeared the same to both eyes (Gräf's Archiv, vol. xxvii.). Therefore some addition is necessary to produce the deeper violet tints of the spectrum; and this can only be obtained by supposing that the violet rays affect the red colour-sense as well as the blue one.

This hypothesis, that violet results from combining the blue and red colour-sensations, is part of Professor Preyer's theory (see Sect. 38 of his paper in Pflüger's Archiv), and seems to me to be supported by several other facts.

(1) As I have already mentioned, when an object is viewed more and more indirectly, so that its image moves from the yellow spot towards the circumference of the retina, sensibility to yellow and blue lasts longer than the sensibility to red and green. On the other hand, if the angular magnitude of a coloured object be diminished, sensibility to red and green lasts longer than sensibility to blue and yellow. In each case violet behaves like a compound of blue and red. As the image moves towards the circumference of the retina, the violet object passes through blue into, white, the red fading first; while, as the angular magnitude of a violet object is diminished, it becomes reddish (v. Kries, Gesichtsempfindungen, p. 93).

(2) Again, Nuel (Annales de l'Oculiste, 80, 82, cited by v. Kries, p. 154) describes how in a certain case of acquired colour-blindness "violet appears blue, red and green white." Similarly Schön states that in cases of atrophy of the optic nerve, when green, red, and yellow are no longer recognized, blue alone is correctly designated, and violet is distinguished as dark blue(Lehre vom Gesichtsfelde, p. 23, cited by von Kries, p. 155).

(3) I have already mentioned a case of yellow-blue blindness described by Stilling, in which blue and violet were, in a faint spectrum, designated as red, though in a brighter spectrum they seem to have appeared grey.

All these facts seem to me to point to violet being the result of affecting at once the blue and red colour-senses.

I am moreover disposed to think that, in addition to the two pairs of complementary colour-senses, there is a fifth coloursense for white.

Inasmuch as

$$
\mathrm{R}+\mathrm{G}=\mathrm{Y}+\mathrm{B}=\text { White, }
$$


we have the two linear equations between five colour-sensations which are required to satisfy the laws which Maxwell and Helmholtz established. Therefore the hypothesis of a fifth, white, colour-sense is admissible.

That the eye does perceive white separately from any other colour is rendered at least probable by considering some particular cases in which this seems to occur.

(1) When an object is viewed indirectly, so that the image falls upon a part of the retina at a sufficient distance from the yellow spot, it will appear white or grey, whatever its actual colour may be (ron Kries, pp. 91-95).

(2) If the angular dimensions of a coloured object be diminished, it will ultimately appear white or grey (von Kries, pp. 87, 94).

The more probable explanation in both these cases seems to be that the other colour-senses are no longer affected by the object, and only the white colour-sense remains affected by it.

(3) Every colour when intensely lighted up appears white (von Kries, p. 81). A not improbable explanation of this seems to be that the other colour-senses are only capable of being affected by light to a limited extent as compared with the white colour-sense.

(4) In cases of atrophy of the optic nerve the perceptions of different colours are gradually lost, until at length every colour appears grey (von Kries, p 154).

(5) There are also cases of total colour-blindness from birth, when every thing appears of the same colour with only different degrees of light and darkness. When this affects both eyes completely, it is of course impossible to predicate with absolute certainty what colour is perceived. But Becker (Gräf's Archiv, vol. xxv.) describes a case where only one eye was so affected, the other having normal vision; and I have seen another case described in which one half of each eye was completely colour-blind, the other half being normal. In each of these cases the colour-blind vision was of white. This white vision must have been arrived at either through the other colour-senses having been lost, leaving a white coloursense behind, or through their having been modified into white. 